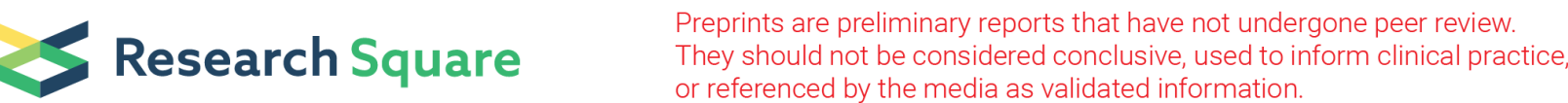

\section{Effectiveness of custom-made foot orthoses vs heel lifts in children with Calcaneal Apophysitis (Sever disease): a CONSORT-compliant randomized trial}

Javier Alfaro-Santafé

Fundacio Universitaria del Bages

Antonio Gómez-Bernal ( $\sim$ agomez@umanresa.cat )

Fundacio Universitaria del Bages

Carla Lanuza-Cerzócimo

Fundacio Universitaria del Bages

José Víctor Alfaro-Santafé

Fundacio Universitaria del Bages

Aitor Pérez-Morcillo

Fundacio Universitaria del Bages

Alejandro Jesús Almenar-Arasanz

Universidad San Jorge

Research article

Keywords: Calcaneal apophysitis, children Sever disease, treatment, orthoses.

Posted Date: April 9th, 2020

DOI: https://doi.org/10.21203/rs.3.rs-20702/v1

License: (c) (i) This work is licensed under a Creative Commons Attribution 4.0 International License.

Read Full License 


\section{Abstract}

Background: Calcaneal apophysitis (Sever disease) is a benign ailment which causes heel pain in children. Conservative treatment strategies are widely popular and the prescription of prefabricated orthoses and heel-lifts is very widespread. The aim of the present research was to determine the effectiveness to relieve calcaneal apophysitis pain using "off-the-shelf" heel-lifts and custom-made orthotics.

Methods: Two intervention modalities were evaluated and compared in a 12-week follow-up randomized comparative effectiveness trial. Inclusion criteria included 9 to 12 years old boys or girls diagnosed of calcaneal apophysitis, primary exclusion criteria included children who had suffered from foot trauma on the heel or had received previous treatment. Children were stratified randomized into experimental (custom-made polypropylene foot orthoses) and control ("off-the-shelf" heel-lifts) group. The primary outcome was calcaneal apophysitis pain perception, which was assessed by the Visual Analogical Scale (VAS), the algometry threshold and the Sport Activity Pain perception. Points of measure were at baseline and after the follow-up period. Analysis was performed according to the intention-to treat principles.

Results: A total of 208 patients were included. Overall, 9 patients were lost to follow-up. Experimental group showed an increase in threshold algometry by $53.4 \%$ (95\% Cl $47.1 \%$ to $59.7 \%)$, a decrease in VAS by $-68.6 \%(95 \% \mathrm{Cl}-74.5 \%$ to $-62.7 \%)$ and a 20.8 times higher probability of improvement of Sport Activity $(95 \% \mathrm{Cl} 8.9$ to 48.6$)$, compared with control group $(p<0.001)$.

Conclusions: Calcaneal apophysitis pain perception was improved in both groups custom-made foot orthoses and heel-lifts, but the experimental group revealed significant changes compared with control group. Children who used custom-made foot orthoses had greater probabilities to improve. Physicians should consider these findings in order to prescribe the most effective treatment in the approach of the calcaneal apophysitis.

Trial registration: ClinicalTrials.gov Identifier: NCT03960086.

\section{Background}

Calcaneal apophysitis (Sever disease) is a very common ailment present in the heel of children between 7 and 15 years old (1-5). Modern literature describes calcaneal apophysitis as a syndrome caused by overuse, resulting from the production of repetitive micro-traumas (3). Mechanical etiology relates the injury to the traction forces of triceps surae and plantar fascia on the calcaneus bony surface (3-6). The anatomical unit named "Achilles-calcaneus-plantar System" (ACPS) describes the functional connection between the Achilles tendon, the calcaneus bone and the plantar fascia (6). There, the posterior trabecular calcaneal system works as a sesamoid bone between the fascia and the tendon fibers (6). Therefore, repetitive stress of the Achilles tendon and the plantar fascia is transmitted on the calcaneus surface affecting bone remodeling: creating perpendicular fibrous bands of cartilage in the 
secondary ossification center of the calcaneus (7). All this, in addition to repetitive impacts on the bony surface constitutes the focus of calcaneal apophysitis (5-8).

Calcaneal apophysitis, fortunately, is a benign ailment which disappears without exception after puberty when the secondary ossification center of the calcaneus is closed (9). Unfortunately, nowadays no evidence-based treatments are available (10). Nevertheless, conservative ones are the most commonly used; these include: sport activity modification, stretching and strengthening exercises and the application of podiatric strategies (heel-lifts and foot orthoses) $(5,9-12)$.

Conservative strategies described in the foregoing paragraph are widely popular (10), but present a number of drawbacks. Activity cessation means an increase of sedentary lifestyle, which is a major factor in obesity (13). The prescription of "off-the-shelf" heel-lifts is very widespread (9-12). These reduce pain perception due to the elevation of the heel, shortening the distance between the origin of the triceps surae muscle and its insertion on the calcaneus (12). Unfortunately heel-lifts do not act perfectly on the mechanical etiology of calcaneal apophysitis $(3,6,8)$. Heel-lifts only act on Achilles tendon traction, but have no impact on plantar fascia and dissipating the impacts on the bony surface of the calcaneus $(8,9)$.

Following this line, there are some studies in literature that have used orthoses to act both on ACPS and repetitive impacts $(8,11,12,14-16)$. Orthoses provide support in the medial arch (relaxing plantar fascia), include a heel-lift component and a wider support surface (dispelling impacts) $(8,11,12,14-16)$.

The available evidence reported the use of orthoses $(8,11,14)$, but most of them were prefabricated and the studies revealed statistical shortcomings and methodological concerns that limit the validity of the results reported $(8,16)$. Nor studies have previously compared the use of "off-the-shelf" heel lifts with custom-made orthotics (16). Based on that, the present research aimed to provide a pragmatic randomized comparative effectiveness trial with an intervention period of 12 weeks, with the aim to compare heel pain perception in children with calcaneal apophysitis using custom-made polypropylene foot orthoses and "off-the-shelf" heel-lifts. Therefore, it was hypothesized that the primary outcome, pain relief, would be significantly improved with the custom-made orthosis compared to the heel-lift.

\section{Methods}

The study was a parallel-group, randomized comparative effectiveness trial with concealed allocation, blinding of investigators and assessors and intention-to-treat analysis. It examined the effect of custommade foot orthoses and heel-lifts in children with calcaneal apophysitis. Participants were enrolled at the time of calcaneal apophysitis diagnosis. After baseline assessment, children were individually randomized to "custom-made foot orthoses" (experimental group) or "off-the-self heel-lifts" (control group). Concealed allocation was carried out by having randomization performed by a third party who was not involved in the recruitment and treatment of the children. Eight permuted blocks were used to stratify randomization by BMI ( 20 or lower, versus $>20 \mathrm{~kg} / \mathrm{m}^{2}$ ), Lunge Test ( $35^{\circ}$ or lower, versus $>35^{\circ}$ of dorsal flexion), FPI-6 (4 or lower, versus $>4$ ) and by VAS score (74 or lower, versus $>74 \mathrm{~mm}$ ) because 
these were considered as important risk factors associated with pain severity in calcaneal apophysitis (2, $17,18)$. A researcher who was unaware of the randomized group allocation measured the outcomes at baseline and 12 weeks later. The design of the present investigation was based on and executed according to the CONSORT Statement. The study was approved by the Ethics Committee of Clinical Research of Aragón (C.P.-C.I.PI16/0303) and registered at ClinicalTrials.gov (NCT03960086).

\section{Participants}

All children with calcaneal apophysitis diagnosis who came for an orthopaedic treatment at Podoactiva Headquarters Podiatric Clinic between September 2015 and April 2018 were assessed for study eligibility prior treatment application. Inclusion criteria included boys and girls between 9 and 12 years old diagnosed radiologically with calcaneal osteochondritis (12). Children were excluded if they: had suffered some trauma on the heel in the past 2 months; had received anti-inflammatory drugs and/or physical treatment for pain in the past 3 months; had presented physical or neurological impairment; or were not interested. Informed consent form with parents' and children authorization was required to be part of the study.

\section{Interventions}

Before treatment application, all children received the following information about conservative strategies for pain reduction: triceps surae stretching, sport activity intensity reduction but no cessation and 10 minutes of ice application for pain exacerbation (10).

Each intervention (custom-made foot orthoses and heel-lifts), consisted of a treatment period of 12 weeks, following the design of previous studies (10). Both interventions were prescribed, designed and fabricated by a Podiatrist expert in orthopaedics, who was unaware of the randomized group allocations.

\section{Experimental group}

Children in the experimental group received as treatment intervention custom-made foot orthoses. The orthoses had a thickness of $9 \mathrm{~mm}$ and were composed by the following materials: confortene, polypropylene, poron XRD and lunasoft (Fig. 1). These kind of orthoses have been previously used in the literature (19). Children were advised pragmatically to wear the orthoses at least 8 to 10 hours per day and during sport activity.

\section{Control group}

Children in the control group received as treatment intervention an $8 \mathrm{~mm}$ "off-the-shelf" heel-lift. These were composed by confortene, poron XRD and Ethyl Vinyl Acetate (EVA) (Fig. 2). These types of heel-lifts have been used before by other authors $(8,10)$. Children were advised pragmatically to wear the heel-lifts at least 8 to 10 hours per day and during sport activity. 
Children were blinded to group allocation. Regardless to experimental or control group they received the same attention during the consultation and they were informed that the intervention given was adequate for their disease, before treatment application and after the follow-up.

\section{Outcome measures}

The primary outcome and the characteristics of the sample of the present research were obtained at baseline and after 12 weeks of follow-up, by an experienced and trained assessor who was blinded to group allocation. At baseline participant's weight and height were measured with an Año-Sayol scale and stadiometer, respectively (Año-Sayol SL, Barcelona, Spain).

The primary outcome was calcaneal apophysitis pain perception, which was determined by the VAS, the algometry threshold and by the following question: "Do you have pain at sport activity?" which had to be answered by YES or NO (Sport Activity Pain dependent variable). The VAS is commonly used to measure pain perception (20), and has been used before to measure pain perception in children with calcaneal apophysitis $(14,17)$. The VAS is described as a horizontal line $100 \mathrm{~mm}$ in length, where at each end points the words "No pain" and "Worst imaginable pain" are placed $(20,21)$. Participants were asked to mark the VAS line at the point which best represented their pain intensity (18). Algometry is commonly used to measure pressure-pain threshold (22). To perform the algometry, the Wagner FPX ${ }^{\mathrm{TM}} 25$ Algometer $^{\circ}$ (Wagner Instruments ${ }^{\circledR}$, USA) was used. It had been used before in children with calcaneal apophysitis (10). To perform the algometry children were asked to lie down in prone position on the stretcher, with knee and ankle bent $90^{\circ}$. Then the algometer was positioned on the Achilles tendon insertion on the calcaneus. Three separate measurements were obtained and the average of them was taken as algometry value (10).

Values for the BMI, FPI- 6 and the Lunge Test in the children with calcaneal apophysitis were taken as baseline characteristics of the sample. The FPI-6 was performed following the guidelines of Redmond et al. (23). FPI is a 6-point tool for clinical assessment, which evaluates the multisegmental nature of foot posture in the three spatial dimensions. Each component of the test is graded between -2 and +2 (signs of supination or pronation), where neutral is graded with 0 . Finally, when the score ranges from 0 to 5 the foot is considered as normal; pronated when it ranges from 6 to 9; highly pronated when > 10; supinated when it ranges from - 1 to -4 ; and highly supinated when a score from - 5 to -12 is obtained (23-25). Lunge Test is commonly used to determine ankle dorsiflexion restriction and shortness in triceps surae muscle $(2,25)$. Restriction in the length of this muscle is considered when the dorsal flexion of the ankle is less than $38-35^{\circ}(2,5,24,25)$.

\section{Data analysis}

Sample size estimation was based on the detection of a difference of $29 \%$ in the number of children with pain; and a mean difference of 0.39 or superior for the algometry and the VAS, between baseline and after the follow up based on a previous pilot study (2). Assuming a two-side a of 0.05 , power of $80 \%$, and a $10 \%$ drop-out rate, a sample size of 198 participants was required. Continuous variables were expressed 
as mean \pm standard deviation (SD) whereas qualitative variables were expressed as frequencies and percentages. Continuous data were checked for normality by Kolmogorov-Smirnov Test.

The baseline characteristics of the children were summarized using descriptive statistics and tabulated for comparison between both groups. Baseline characteristics were compared between included and excluded participants to analyze whether they were representative. Mann-Whitney $\mathrm{U}$ and T-Student Tests were used to compare continuous variables and the Fisher Test to compare dichotomous variables.

Differences between baseline and final assessment were performed using the average-to-average method. Mann-Whitney U Test was used to compare absolute and relative changes in algometry and VAS. McNemar Test was applied to calculate the improvement, which was positive when patients changed from pain situation to no pain situation for the dependent variable Sport Activity Pain. Identifying treatment effectiveness after the follow-up was made by regression models. Linear regression was applied to quantitative variables, algometry and VAS, and logistic regression to dichotomous qualitative variables, association was measured in terms of odds ratio.

Statistical analysis of the outcomes was performed according to intention-to-treat principles compared the groups regarding pain perception evolution. For all tests, a two-sided p-value $<0.05$ was considered significant. The statistical analyses were performed using the SPSS software 22.0 for Windows (SPSS Ibérica, Madrid, Spain).

\section{Results}

\section{Enrollment and characteristics of the participants}

Between September 2015 and April 2018, 234 children were screened, 208 of them were included in the present study. Among these, 104 children were allocated to both the experimental and the control group. The flow of participants through the study is presented in Fig. 3 and baseline characteristics in Table 1. No significant demographic differences were found between the two groups. BMI values suggested that children in both groups were normal-weight, Lunge Test values were lower than $35^{\circ}$ and FPI-6 ones were greater than eight $(>4)$, in both groups respectively. Results showed that children had respectively shortened triceps surae muscle and pronated feet. 
Table 1

Baseline characteristics of the children with calcaneal apophysitis

\begin{tabular}{|c|c|c|c|c|}
\hline Characteristic & $\begin{array}{l}\operatorname{Exp} \\
(n=104)\end{array}$ & $\begin{array}{l}\text { Con } \\
(n=104)\end{array}$ & ICC & $p$ value \\
\hline Age (years.month) & $11.1 \pm 1.0$ & $11.3 \pm 1.0$ & & $0.133^{a}$ \\
\hline Male [n (\%)] & $85(82.2)$ & $88(84.4)$ & & $0.842^{\mathrm{b}}$ \\
\hline BMI $\left(\mathrm{kg} / \mathrm{m}^{2}\right)$ & $19.2 \pm 2.3$ & $19.4 \pm 2.4$ & & $0.677^{a}$ \\
\hline FPI-6 right & $8.3 \pm 1.7$ & $8.2 \pm 1.7$ & & $0.477^{\mathrm{c}}$ \\
\hline FPI-6 left & $8.3 \pm 1.7$ & $8.2 \pm 1.7$ & & $0.580^{c}$ \\
\hline Lunge right (degrees) & $32.3 \pm 3.5$ & $32.1 \pm 3.7$ & & $0.761^{\mathrm{c}}$ \\
\hline Lunge left (degrees) & $32.4 \pm 3.5$ & $32.0 \pm 3.7$ & & $0.447^{c}$ \\
\hline VAS (mm) & $80.1 \pm 13.1$ & $81.3 \pm 13.2$ & & $0.559^{c}$ \\
\hline Algometry (kgf) & $2.9 \pm 0.4$ & $2.7 \pm 0.4$ & $0.91[0.88-0.94]$ & $0.026^{c}$ \\
\hline $\begin{array}{l}\text { Sport Activity Pain } \\
\text { [n (\%)] }\end{array}$ & $103(98.9)$ & $101(96.7)$ & & $0.621^{b}$ \\
\hline \multicolumn{5}{|c|}{$\begin{array}{l}\text { Con = control group, Exp = experimental group, BMI = Body Mass Index, FPI- } 6=6 \text { Item Foot Posture } \\
\text { Index, VAS = Visual Analogue Scale, ICC = Intraclass Correlation Coefficient }\end{array}$} \\
\hline \multicolumn{5}{|c|}{${ }^{\mathrm{a}}$ T-Student Test; ${ }^{\mathrm{b}}$ Fisher Test; ${ }^{\mathrm{c}}$ Mann-Whitney U Test. } \\
\hline \multicolumn{5}{|c|}{$\begin{array}{l}\text { Qualitative variables are expressed as } n(\%) \text {, quantitative variables as Mean } \pm \text { SD. Significant at } p< \\
0.05 . \mathrm{mmm}\end{array}$} \\
\hline
\end{tabular}

\section{Outcomes}

The primary outcome of calcaneal apophysitis pain perception analysis is shown in Table 2. Bigger changes and improvements were noted for the groups where participants used custom-made foot orthoses. Differences between baseline and final assessment were statistically significant $(p<0.05)$ for both interventions. Values for VAS decreased $68.5 \pm 15.4$ points in the experimental group $(p<0.001)$ and $14 \pm 17.7$ points in the control group $(p<0.001)$; algometry values increased $2.0 \pm 0.5 \mathrm{kgf}$ in the experimental group $(p<0.001)$ and $0.6 \pm 0.6 \mathrm{kgf}$ in the control group $(p<0.001)$; the number of children who presented Sport Activity Pain reduced from 103 to 7 in the experimental group $(p<0.001)$ and from 101 to 66 in the control group $(p<0.001)$. Differences in changes and improvement between experimental and control group are shown in Fig. 4 and were statistically significant for all the variables $(p<0.001)$. 
Results were compared between groups using odds ratio and the confidence intervals were wide, as shown in Table 2.

Table 2

Outcomes at final assessment.

\begin{tabular}{|c|c|c|c|c|c|c|c|c|c|}
\hline Outcome & Groups & & & & & & & & \\
\hline & Exp & & & & & Con & & & $(95 \%$ \\
\hline & $(n=10 c$ & & & & & $(n=99$ & & & $\mathrm{Cl})^{*}$ \\
\hline & Final & $C \%$ & $\operatorname{Imp} \%$ & $\begin{array}{l}\mathrm{p}- \\
\text { value }\end{array}$ & Final & $\mathrm{C} \%$ & Imp\% & $\begin{array}{l}\mathrm{p}- \\
\text { value }\end{array}$ & \\
\hline VAS (mm) & $\begin{array}{l}11.6 \\
\pm 17.4\end{array}$ & $\begin{array}{l}-88.4 \\
\pm 18.5\end{array}$ & & $\begin{array}{l}< \\
0.001^{\mathrm{a}}\end{array}$ & $\begin{array}{l}67.3 \\
\pm \\
21.2\end{array}$ & $\begin{array}{l}-19.2 \\
\pm \\
22.2\end{array}$ & & $\begin{array}{l}< \\
0.001^{\mathrm{a}}\end{array}$ & $\begin{array}{l}-68.6 \\
(-74.5 \\
\text { to } \\
-62.7)\end{array}$ \\
\hline Algometry (kgf) & $\begin{array}{l}4.9 \pm \\
0.5\end{array}$ & $\begin{array}{l}73.0 \pm \\
23.6\end{array}$ & & $\begin{array}{l}< \\
0.001^{\mathrm{a}}\end{array}$ & $\begin{array}{l}3.3 \pm \\
0.7\end{array}$ & $\begin{array}{l}19.6 \\
\pm \\
18.7\end{array}$ & & $\begin{array}{l}< \\
0.001^{\mathrm{a}}\end{array}$ & $\begin{array}{l}53.4 \\
(47.1 \\
\text { to } \\
59.7)\end{array}$ \\
\hline $\begin{array}{l}\text { Sport Activity } \\
\text { Pain [n (\%)] }\end{array}$ & $7(7)$ & & 91.1 & $\begin{array}{l}< \\
0.001^{\mathrm{b}}\end{array}$ & $\begin{array}{l}66 \\
(66.7)\end{array}$ & & 33.3 & $\begin{array}{l}< \\
0.001^{\mathrm{b}}\end{array}$ & $\begin{array}{l}20.8 \\
(8.9 \\
\text { to } \\
48.6)\end{array}$ \\
\hline a Mann-Whitney & Test. ${ }^{b} \mathrm{~N}$ & Vemar & t. *Exp & imental & oup as & eferenc & & & \\
\hline Change (C \%) an & Improve & ent (Imp & ) are ca & ulated c & mpared & vith bas & ine (Tab & 1). & \\
\hline
\end{tabular}

Odds ratio $(95 \% \mathrm{Cl})$ between groups showed that children who wore custom-made foot orthoses had the probability to increase algometry data by 53.4 (47.1 to 59.7 ), to reduce VAS by 68.6 (74.5 to 62.7); and a probability of 20.8 (8.9 to 48.6 ) to improve Sport Activity Pain, compared with children who wore heellifts.

\section{Discussion}

The purpose of this trial was to compare heel pain perception in children with calcaneal apophysitis using custom-made polypropylene foot orthoses and "off-the-shelf" heel-lifts in an intervention period of 12 weeks. Calcaneal apophysitis pain perception for the three variables measured by: VAS, algometry and the question "Do you have pain at sport activity?", was significatively improved and reduced in both groups. Experimental group showed a significant pain relief due to the use of the custom-made foot orthoses, compared with control group. 
At baseline almost the whole sample (98.1\%) presented Sport Activity Pain and all the participants had high VAS values and a reduced pressure-pain threshold on the affected heel. Pain relief was significantly different between experimental (custom-made foot orthoses) and control (heel-lifts) groups.

Heel-lifts function was to lift the heel with an inclined plane, which allowed to diminish Achilles tendon tension and traction on the calcaneus bony surface $(3,8-10)$. On the other hand, custom-made foot orthoses provided in the heel a lift-rise component, an increased support surface covering calcaneus plantar face reducing repetitive impacts, as well as a pronation correction component tailored to the foot of each child $(3,8,10,26)$.

Improvement in the control group was produced approximately in $20-30 \%$ of children, while in experimental group in $70-90 \%$ of children $(p<0.001)$. Experimental group compared with control group, experimented a raising in algometry threshold by $53.4 \%$, a VAS punctuation reduction of $-68.6 \%$ and a 20.8 times higher probability to improve Sport Activity Pain. Similar results were obtained in 2011, in two studies performed by Perhamre et al. $(8,9)$. In their research authors compared a heel-cup $(3 \mathrm{~mm})$, which reduced repetitive impacts with a wedge that lifted the heel $(5 \mathrm{~mm})$, in 51 boys with calcaneal apophysitis; the cup produced pain reduction by $80 \%$, due to its higher impact absorption. They employed the Borg CR-10 visual analogue scale, obtaining a significant decrease in pain levels from 7 to 2 . Between 2010 and 2016 James et al. (14), performed a randomized controlled trial where they compared the effectiveness of a heel-lift ( $6 \mathrm{~mm}$ EVA) with a prefabricated foot orthosis (polyurethane). At the beginning, their study was going to last 3 months but at the end lasted 12 months. Pain intensity was measured by "Faces pain scale", not obtaining differences between the two treatment tools in the 12 months follow-up. In the present study we have seen significant differences in 12 weeks intervention period. Calcaneal apophysitis is considered a disease of growth age which will disappear at the end of the calcaneus ossification, i.e., long-term monitoring results may not be significant $(9,10)$. James et al. $(14)$ also did not employ an individualized treatment, while they applied prefabricated foot orthoses. In our case, custommade foot orthoses were individually adapted as Landorf et al. recommend (27).

Others interesting findings were that children in both groups had high BMI (17), presented flat feet and shortened triceps surae muscle according to FPI-6 (> 8 in both groups) (23) and Lunge Test values $\left(<35^{\circ}\right.$ in both groups) $(2,25)$. In the current literature we can find several studies in which authors have analyzed the relationship between FPI-6, calcaneal apophysitis, weight and age (17,28-31). In 2015, Evans and Karimi (30), analyzed the relationship between BMI and FPI-6 in 728 overweight and healthy children between 3 and 15 years of age, they did not find a significant association between BMI and flat feet. Gijon-Nogueron et al. (29), evaluated in a cross-sectional study 1,762 school children between 6 and 11 years of age, without pain and/or injury in the feet and lower limbs. Results showed the generallyaccepted margins of neutral FPI-6 (0 to 4). Martínez-Nova et al. (28), supported the FPI-6 results provided by Gijon-Nogueron et al. (29), in healthy children. In another study, performed by James et al. (17) they recruited 124 children with calcaneal apophysitis between 8 and 14 years of age. The authors found that children had a higher BMI and FPI-6, while, according to the authors ankle range of motion was increased, but Lunge Test showed values close to ours, which showed ankle dorsiflexion restriction, suggesting 
passive tension in the gastrocnemius/soleus complex (2). In the same line, Hawke et al. (31) found a relationship between flat feet and ankle dorsiflexion limitation assessed by Lunge Test in 30 healthy children between 7 and 15 years of age. Our sample was composed exclusively by children with calcaneal apophysitis that presented flat feet, as well as higher BMI. In their research, James et al. (17), observed that these were risk factors associated with calcaneal apophysitis pain. Furthermore, we noted an association of ankle dorsiflexion restriction with flat feet (31). FPI-6 and Lunge Test values found in the present research suggested that there are two structures of ACPS in tension $(2,23,31)$. In his research, Huerta (6), showed the relationship between triceps surae muscle and plantar fascia, and how the tightness in the muscle increases Achilles tendon tension, which is reflected as ankle dorsiflexion stiffness and plantar fascia tension during weight-bearing activities. Achilles tendon and plantar fascia tension is transmitted on the calcaneus bone, affecting bone remodelling in the secondary ossification center of the calcaneus producing pain $(5,7,15)$.

Our findings suggest that children with calcaneal apophysitis present a higher $\mathrm{BMI}$, flat feet and ankle dorsiflexion restriction due to a shortened triceps surae $(2,17,23)$. Therefore, soft structures of the ACPS are in tension (6), thus an holistic approach of the ASPS is necessary to reduce stress on the calcaneal bony surface. Heel-lift acted exclusively on the Achilles tendon, which is an insufficient approach of the mechanical etiology of this disease: ACPS traction and repetitive impacts $(3,6,8)$. On the other hand, custom-made foot orthosis included a rise component (for Achilles tendon relaxation) in its design, a wider surface (calcaneus bone) and a pronation correction (plantar fascia), acting on the whole ACPS (6, 8). Custom-made polypropylene foot orthoses, provide a constant muscle-fibrous relaxation feedback between the structures of the ACPS which made them significatively greater relieving pain than the "offthe-shelf" heel-lifts.

Apart from the results found, some limitations need to be considered. First, children in both groups wore their respective treatment on their own footwear, rather than on a standardized shoe. Second, level of physical activity of each participant was not considered. Third, follow up period lasted 3 months, therefore changes in short or long-term periods were not investigated. The present study provides new information about calcaneal apophysitis approach. As strengths, participants and assessors were blinded, sample size was enough to show reliable results, stratified randomization was performed in eight permuted blocks considered as important risk factors in calcaneal apophysitis pain, both groups (experimental and control) were homogeneous and the study provided consistent data about the use of custom-made foot orthoses for calcaneal apophysitis pain relief.

\section{Conclusions}

The potential of a holistic approach of the calcaneal apophysitis by the use of custom-made foot orthoses needs to be considered in further approaches and treatment strategies. In future studies, new mechanical etiological factors and clinical tests related with the presence of calcaneal apophysitis should be identified. Different long-term monitoring to prescribe the most effective approach, have to be considered. 
In summary, this study highlights that the use of custom-made foot orthoses instead of heel-lifts for calcaneal apophysitis (Sever disease), applied during a 12 weeks follow-up period may have a substantial effect on calcaneal apophysitis pain relief.

\section{List Of Abbreviations}

VAS: Visual Analogical Scale

BMI: Body Mass Index

FPI-6: 6-Item Foot Posture Index

ACPS: Achilles-calcaneus-plantar System

EVA: Ethyl Vinyl Acetate

\section{Declarations}

Ethics approval and consent to participate

The study was approved by the Ethics Committee of Clinical Research of Aragón (C.P.-C.I.PI16/0303)

The consent to participate was written and approved by the Ethics Committee of Clinical Research of Aragón. Every participant had to signed it before be enrolled in the study.

Consent for publication

Not applicable

Availability of data and materials

The datasets used and/or analysed during the current study are available from the corresponding author on reasonable request.

Competing interests

The authors declare that they have no competing interests.

Funding

We have received no funding to perform this research.

Authors' contributions

JA-S had the original idea of the present research, he designed the protocol, evaluated the children and designed the treatment. AG-B evaluated the children at baseline and after the follow-up. CL-C made the 
statistical analysis of the data. JVA-S performed the randomization, AP-M reviewed and wrote the manuscript, Alejandro Jesús Almenar-Arasanz reviewed and wrote the manuscript.

Acknowledgements (Declaration section)

Not applicable.

Authors' information (Declaration section)

All the co-authors of the present research are podiatrists and/or work in the field of podiatry assessing therapeutic protocols, making gait, biomechanical and posture analysis and studies. A very common musculoskeletal pain cause that we are used to manage with in the daily clinic, is calcaneal apophysitis. Reviewing the literature, we realize that there is no agreement for a preferred treatment, and that the evidence about orthopaedic devices in unclear. Based on that, we perform a research where we wanted to provide a pragmatic randomized comparative effectiveness with the aim to compare heel pain perception in children with calcaneal apophysitis using custom-made polypropylene foot orthoses and "off-theshelf" heel-lifts.

\section{References}

1. Madden CC, Mellion MB. Sever's disease and other causes of heel pain in adolescents. Am Fam Physician. 1996 Nov 1;54(6):1995-2000.

2. Alfaro Santafé J, Gómez Bernal A, Alfaro Santafé JV, Lanuza Cerzócimo C, Escamilla Galindo VL, Almenar Arasanz AJ. [Relación de Lunge y Jack Test en la apófisis calcánea (Talalgia de Sever) en futbolistas jóvenes]. [Article in Spanish]. Rev int cienc podol. 2017;11(2):117-23.

3. Tu P. Heel Pain: diagnosis and management. Am Fam Physician. 2018 Jan 15;97(2):86-93.

4. Micheli LJ, Fehlandt AF,Jr. Overuse injuries to tendons and apophyses in children and adolescents. Clin Sports Med. 1992 Oct;11(4):713-726.

5. Hendrix CL. Calcaneal apophysitis (Sever disease). Clin Podiatr Med Surg. 2005 Jan;22(1):55-62.

6. Huerta JP. The effect of the gastrocnemius on the plantar fascia. Foot Ankle Clin, 2014;19(4):701718.

7. Anderson JG, Bohay DR, Eller EB, Witt BL. Gastrocnemius recession. Foot Ankle Clin. 2014 Dec;19(4):767-86.

8. Perhamre S, Lundin F, Norlin R, Klässbo M. Sever's injury; treat it with a heel cup: a randomized, crossover study with two insole alternatives. Scand J Med Sci Sports. 2011 Dec;21(6):e42-7.

9. Perhamre S, Janson S, Norlin R, Klässbo M. Sever's injury: treatment with insoles provides effective pain relief. Scand J Med Sci Sports. 2011 Dec;21(6):819-23.

10. Wiegerinck JI, Zwiers R, Sierevelt IN, van Weert HC, van Dijk CN, Struijs PA. Treatment of calcaneal apophysitis: wait and see versus orthotic device versus physical therapy: a pragmatic therapeutic randomized clinical trial. J Pediatr Orthop. 2016 Mar;36(2):152-7. 
11. Micheli LJ, Ireland ML. Prevention and management of calcaneal apophysitis in children: an overuse syndrome. J Pediatr Orthop. 1987 Jan - Feb;7(1):34-8.

12. Gijon-Nogueron G, Cortes-Jeronimo E, Cervera-Marin JA, García-de-la-Peña R, Benhamu-Benhamu S, Luque-Suarez A. Foot orthoses custom-made by vacuum forming on the non-load-bearing foot: preliminary results in male children with calcaneal apophysitis (Sever's disease). Prosthet Orthot Int. 2013 Dec;37(6):495-8.

13. Reilly JJ, Jackson DM, Montgomery C, Kelly LA, Slater C, Grant S, Paton JY. Total energy expenditure and physical activity in young Scottish children: mixed longitudinal study. Lancet. 2004 Jan 17;363(9404):211-2.

14. James AM, Williams CM, Haines TP. Effectiveness of footwear and foot orthoses for calcaneal apophysitis: a 12-month factorial randomised trial. Br J Sports Med. 2016 Oct;50(20):1268-1275.

15. Scharfbillig RW, Jones S, Scutter SD. Sever's disease: what does the literature really tell us? J Am Podiatr Med Assoc. 2008 May-Jun;98(3):212-23.16.

16. James AM, Williams $C M$, Haines TP. Effectiveness of interventions in reducing pain and maintaining physical activity in children and adolescents with calcaneal apophysitis (Sever's disease): a systematic review. J Foot Ankle Res. 2013 Dec 3;6(1):16.

17. James AM, Williams CM, Luscombe M, Hunter R, Haines TP. Factors associated with pain severity in children with calcaneal apophysitis (Sever disease). J Pediatr. 2015 Aug;167(2):455-9.

18. Jensen MP, Chen C, Brugger AM. Interpretation of visual analog scale ratings and change scores: a reanalysis of two clinical trials of postoperative pain. J Pain. 2003 Sep;4(7):407-14.

19. Caravaggi P, Giangrande A, Lullini G, Padula G, Berti L, Leardini A. In shoe pressure measurements during different motor tasks while wearing safety shoes: The effect of custom made insoles vs. prefabricated and off-the-shelf. Gait Posture. 2016 Oct;50:232-8.

20. Ferreira-Valente MA, Pais-Ribeiro JL, Jensen MP. Validity of four pain intensity rating scales. Pain. 2011 Oct;152(10):2399-404.

21. Graven-Nielsen T, Vaegter HB, Finocchietti S, Handberg G, Arendt-Nielsen L. Assessment of musculoskeletal pain sensitivity and temporal summation by cuff pressure algometry: a reliability study. Pain. 2015 Nov;156(11):2193-202.

22. Redmond AC, Crosbie J, Ouvrier RA. Development and validation of a novel rating system for scoring standing foot posture: the Foot Posture Index. Clin Biomech (Bristol, Avon). 2006 Jan;21(1):89-98.

23. Hawke F, Rome K, Evans AM. The relationship between foot posture, body mass, age and ankle, lower-limb and whole-body flexibility in healthy children aged 7 to 15 years. J Foot Ankle Res. 2016 Dec 27;9(1):14.

24. Evans AM, Rome K, Peet L. The foot posture index, ankle lunge test, Beighton scale and the lower limb assessment score in healthy children: a reliability study. J Foot Ankle Res. 2012 Jan 9;5(1):1.

25. Banwell HA, Mackintosh S, Thewlis D. Foot orthoses for adults with flexible pes planus: a systematic review. J Foot Ankle Res. 2014 Dec 5;7(1):23. 
26. Landorf K, Keenan AM, Rushworth RL. Foot orthosis prescription habits of Australian and New Zealand podiatric physicians. J Am Podiatr Med Assoc. 2001 Apr;91(4):174-83.

27. Martínez-Nova A, Gijón-Noguerón G, Alfageme-García P, Montes-Alguacil J, Evans AM. Foot posture development in children aged 5 to 11 years: A three-year prospective study. Gait Posture [Internet]. 2018 May;62:280-4.

28. Gijon-Nogueron G, Montes-Alguacil J, Alfageme-Garcia P, Cervera-Marin JA, Morales-Asencio JM, Martinez-Nova A. Establishing normative foot posture index values for the paediatric population: a cross-sectional study. J Foot Ankle Res. 2016 Dec 26;9(1):24.

29. Evans AM, Karimi L. The relationship between paediatric foot posture and body mass index: do heavier children really have flatter feet? J Foot Ankle Res. 2015 Dec 27;8(1):46.

30. Hawke F, Rome K, Evans AM. The relationship between foot posture, body mass, age and ankle, lower-limb and whole-body flexibility in healthy children aged 7 to 15 years. J Foot Ankle Res. 2016 Dec 27;9(1):14.

\section{Figures}

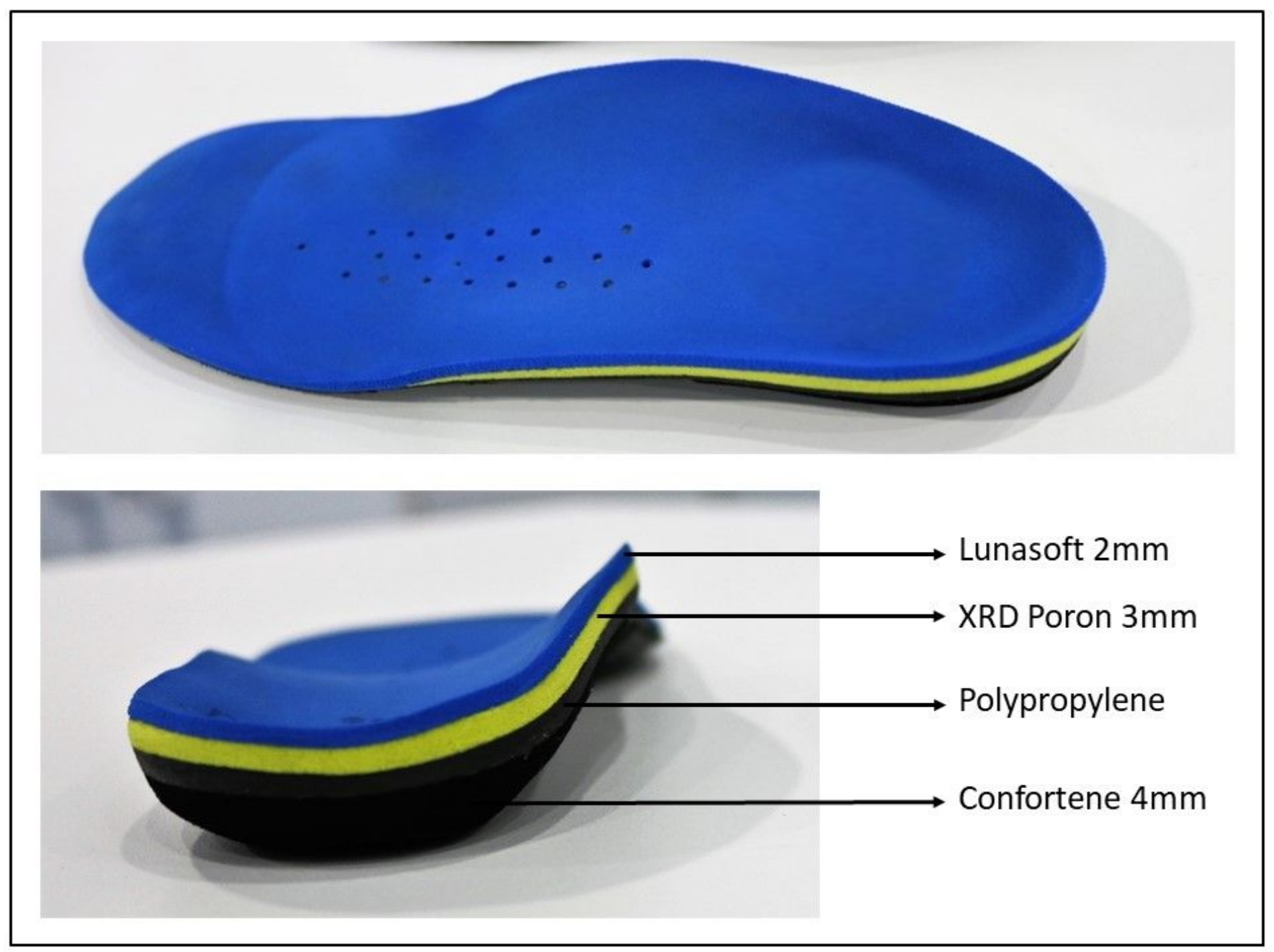


Figure 1

Custom-made polypropylene foot orthosis components.

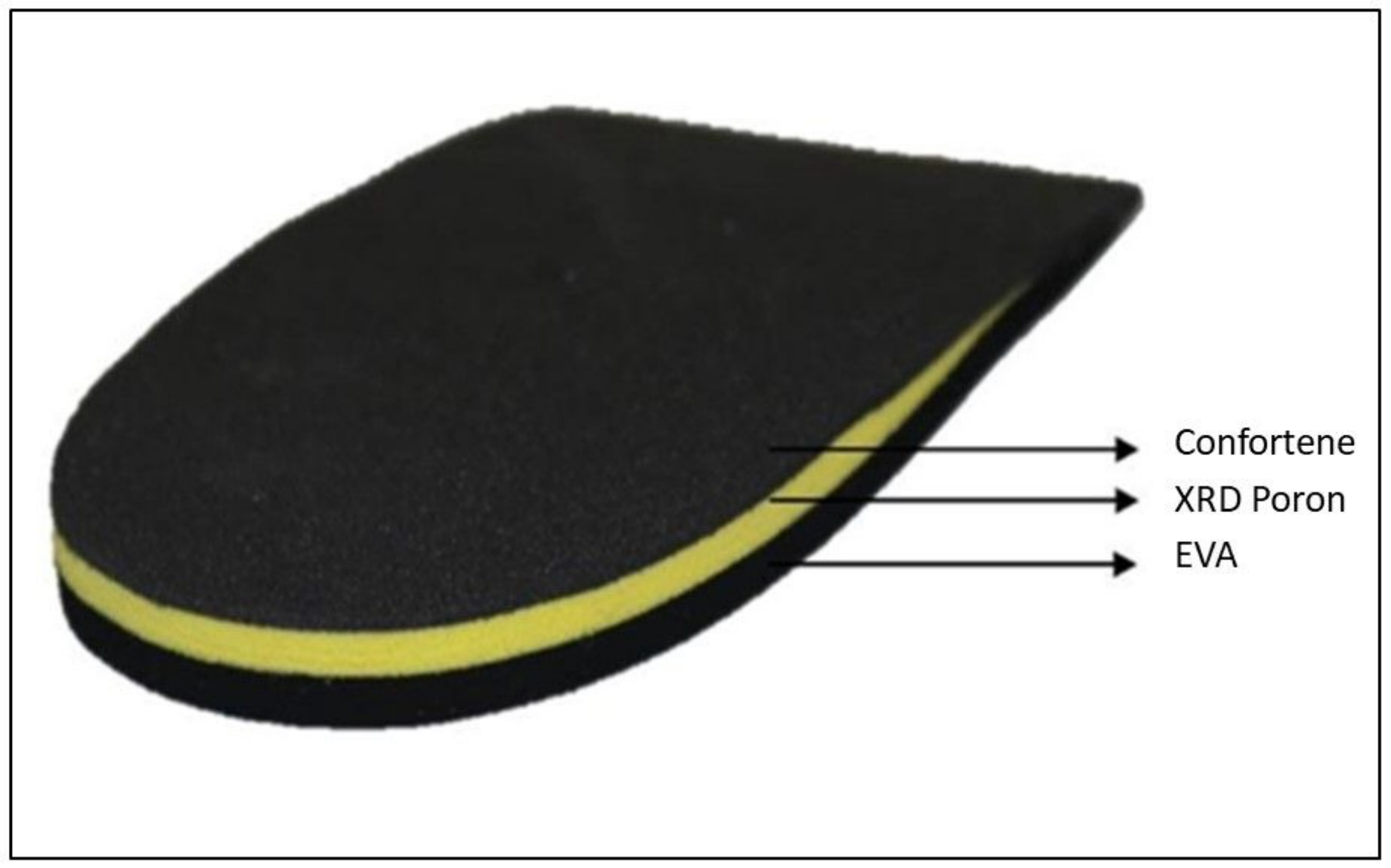

Figure 2

Off-the-shelf heel-lift components. 


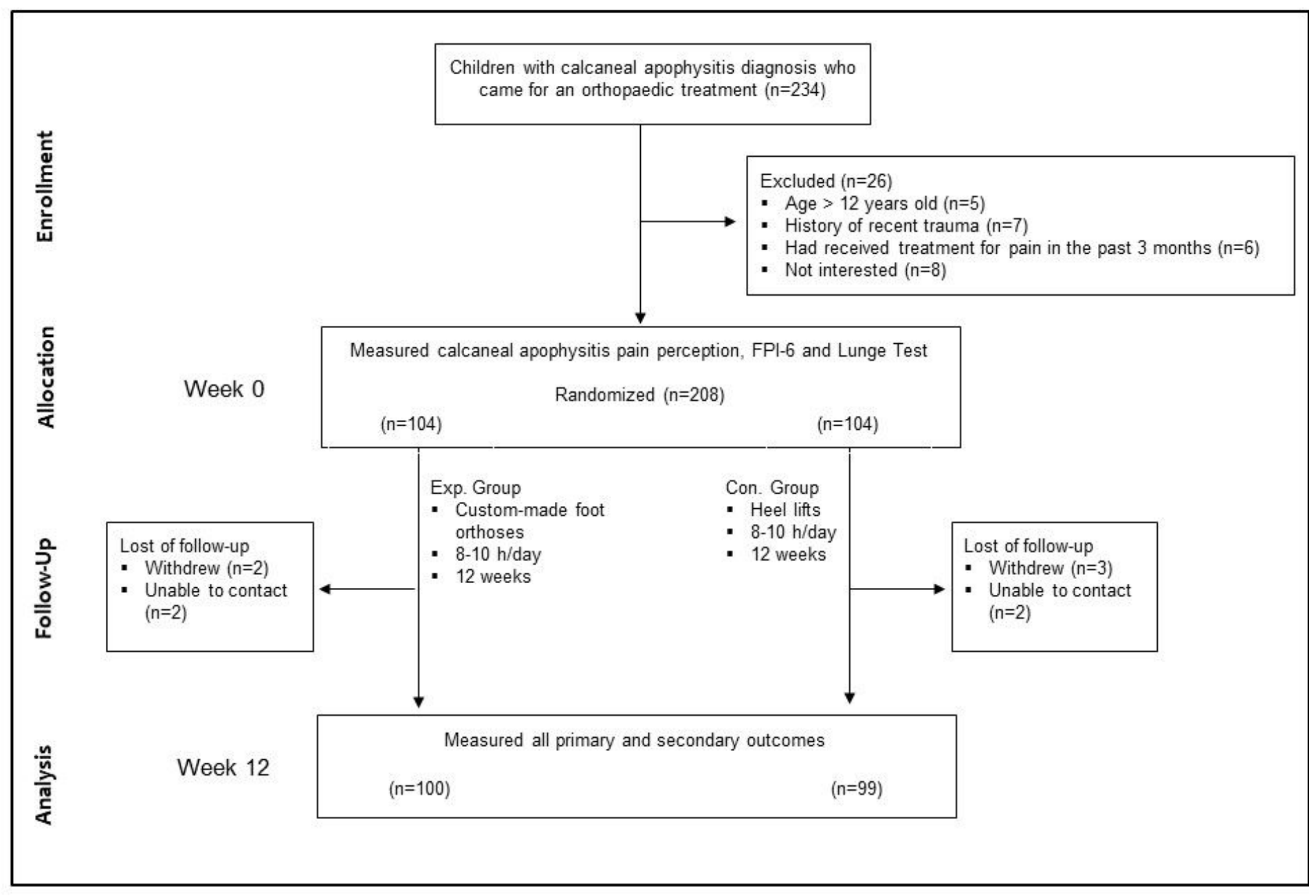

Figure 3

Design and flow of the children through the trial. Con $=$ Control group, $\operatorname{Exp}=$ Experimental group, $\mathrm{FPI}=$ Foot Posture Index 


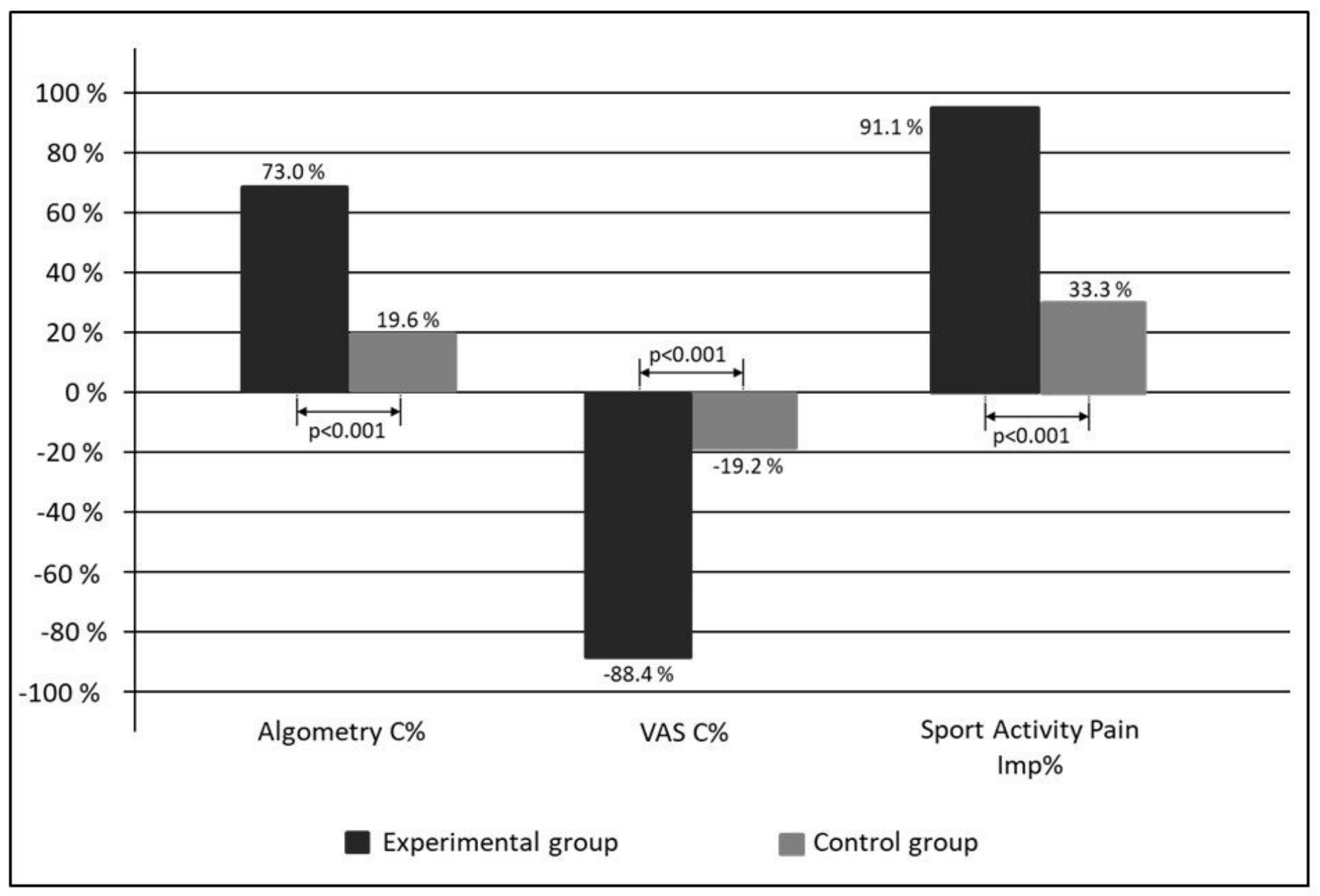

Figure 4

Change and improvement comparison between experimental and control group. $\mathrm{C} \%=$ Change $\%, \mathrm{Imp} \%=$ Improvement \%

\section{Supplementary Files}

This is a list of supplementary files associated with this preprint. Click to download.

- CONSORTChecklist.doc 